\title{
Glial Cell Line-Derived Neurotrophic Factor Is Essential for Postnatal Survival of Midbrain Dopamine Neurons
}

\author{
Ann-Charlotte Granholm, , ${ }^{1,2,3}$ Mary Reyland, ${ }^{1}$ David Albeck, ${ }^{1,3}$ Linda Sanders, ${ }^{1,3}$ Greg Gerhardt, ${ }^{2,3}$ \\ George Hoernig, ${ }^{1}$ Liya Shen, ${ }^{4}$ Heiner Westphal, ${ }^{4}$ and Barry Hoffer ${ }^{5}$
}

Departments of ${ }^{1}$ Basic Science and ${ }^{2}$ Pharmacology and ${ }^{3}$ The Neuroscience Training Program, University of Colorado Health Sciences Center, Denver, Colorado 80262, ${ }^{4}$ National Institute of Child Health and Human Development, LMGD, National Institutes of Health, Bethesda, Maryland 20892, and 5/ntramural Research Program, National Institute of Drug Abuse, Baltimore, Maryland 21224

Glial cell line-derived neurotrophic factor (GDNF) is one of the most potent trophic factors that have been identified for midbrain dopamine (DA) neurons. Null mutations for trophic factor genes have been used frequently for studies of the role of these important proteins in brain development. One problem with these studies has been that often only prenatal development can be studied because many of the knockout strains, such as those with GDNF null mutations, will die shortly after birth. In this study, we looked at the continued fate of specific neuronal phenotypes from trophic factor knockout mice beyond the time that these animals die. By transplanting fetal neural tissues from GDNF -/-, GDNF +/-, and wild-type (WT) mice into the brain of adult wild-type mice, we demonstrate that the contin-

Parkinson's disease (PD) is characterized by a progressive degeneration of midbrain dopaminergic (DA) substantia nigra neurons and a subsequent loss of DA input to the caudate nucleus and putamen (Bernheimer et al., 1973; Hornykiewicz and Kish, 1986). With the progression of the disease, the available pharmacotherapy, involving use of the dopamine precursor L-dopa, becomes less effective and also leads to significant side effects (Hornykiewicz and Kish, 1986; Leenders et al., 1990). Therefore, recent advances in this field have concentrated on neuroprotective therapy to rescue the dopamine neurons.

There are numerous indications from the literature that trophic factors may rescue adult and developing neurons from degeneration. A factor from a glial cell line (rat B49) (Schubert et al., 1974) was found to affect dopamine neurons in tissue culture experiments and was cloned and termed glial cell line-derived neurotrophic factor (GDNF) (Lin et al., 1993). The GDNF family of growth factors also includes neurturin, persephin, and artemin, which have seven conserved cysteine residues with similar spacing, making them distant members of the transforming growth factor- $\beta$ (TGF- $\beta$ ) superfamily (Kotzbauer et al., 1996; Creedon et al., 1997; Saarma and Sariola, 1999). GDNF can promote survival and function of dopamine neurons in vivo, both

Received Oct. 19, 1999; revised Feb. 17, 2000; accepted Feb. 24, 2000.

This work was supported by US Public Health Service Grants AG12122, AG04418, AG15239, and AG10755 as well as a grant from the US Army Medical Research and Materiel command (Grant 98228016).

Correspondence should be addressed to Ann-Charlotte Granholm, Department of Basic Science, Box C286, University of Colorado Health Sciences Center, Denver, CO 80262. E-mail: lotta.granholm@uchsc.edu.

Copyright (C) 2000 Society for Neuroscience $0270-6474 / 00 / 203182-09 \$ 15.00 / 0$ ued postnatal development of ventral midbrain dopamine neurons is severely disturbed as a result of the GDNF null mutation. Ventral midbrain grafts from -/- fetuses have markedly reduced DA neuron numbers and fiber outgrowth. Moreover, DA neurons in such transplants can be "rescued" by immersion in GDNF before grafting. These findings suggest that postnatal survival and/or phenotypic expression of ventral mesencephalic DA neurons is dependent on GDNF. In addition, we present here a strategy for studies of maturation and even aging of tissues from trophic factor and other knockout animals that do not survive past birth.

Key words: trophic factors; GDNF; neurodegeneration; transplantation; neural development; substantia nigra; DA neurons

in the intact rat brain (Hudson et al., 1995) and in adult DA neurons after nigrostriatal lesions (Hoffer et al., 1994; Bowenkamp et al., 1995; Hudson et al., 1995; Johansson et al., 1995; Lindner et al., 1995; Tomac et al., 1995; Gash et al., 1996; Granholm et al., 1997a,b). It has also been shown that GDNF is secreted in the target (striatum) and transported retrogradely to the DA cell bodies in the mesencephalon (Tomac et al., 1996). A critical issue, however, is whether GDNF functions as an endogenous trophic factor, and this could best be examined by nullmutation experiments.

In previous studies, we and others have described the early development of GDNF knockout $(-/-)$ mice, compared with wild-type $(\mathrm{WT},+/+)$ siblings. Abnormalities were detected in both peripheral and central noradrenergic neurons, whereas the mesencephalic dopamine neurons remained intact (Moore et al., 1996; Pichel et al., 1996; Sanchez et al., 1996; Granholm et al., 1997a,b). However, these earlier studies were limited to fetal development, because the GDNF - / - animals die at birth. The major apoptotic waves for midbrain dopamine neurons occur at postnatal day 2 (P2) and P14 in the mouse (Oo and Burke, 1997), and therefore the full effect of the null-mutation may only be seen after this time point.

We therefore designed an experiment in which maturation of dopamine neurons from GDNF - / - fetuses could be studied for long time periods postnatally. Intracranial transplantation of fetal dopamine neurons from the ventral mesencephalon (VM) of GDNF $-/-$, GDNF+/-, or WT fetuses into the dopaminedenervated striatum of adult WT mice was performed. These intracranial transplants of GDNF $-/-,+/-$, and WT dopamine neurons into an adult WT environment would allow us to deter- 
mine the specific role of GDNF for dopamine neuron development at the time of target innervation.

\section{MATERIALS AND METHODS}

Animals. A nonfunctional allele of the GDNF gene was generated by replacing part of the third exon that encodes GDNF protein with a cassette expressing the selectable marker neomycin phosphotransferase, as described previously in detail (Pichel et al., 1996; Granholm et al., 1997a,b). After introducing this construct into embryonic stem cells, six clones were identified with the predicted mutant allele. CD1 or C57BL/6 recipient strains were used to obtain germline transmission of the targeted allele. Four clones produced chimeric mice that transmitted the mutation to their progeny. Heterozygous offspring were viable and fertile, whereas mice homozygous for the mutant GDNF allele (GDNF $-/-$ ) died within $24 \mathrm{hr}$ of birth.

Fetal donors of embryonic day 14-15 (E14-15) were obtained from heterozygous dams and mated to heterozygous males, and the mediolateral section of the VM was dissected and transplanted into adult WT mice. Four weeks before transplantation, the adult recipient mice received daily injections of the DA toxin 1-methyl-4-phenyl-1,2,3,6tetrahydropyridine (MPTP, Research Biochemicals International), 30 $\mathrm{mg} \cdot \mathrm{kg}^{-1} \cdot \mathrm{d}^{-1}$ intraperitoneally for 4 consecutive days as described previously (Tomac et al., 1995), giving rise to a significant decrease in striatal dopamine levels to allow identification of grafted DA elements. The fetal VM tissue from GDNF-,$-+/-$, and $+/+$ fetuses was transplanted intracranially into the dorsal striatum, as described in previous protocols (Strömberg et al., 1985; Granholm et al., 1997a,b). Pregnant heterozygous mice were anesthetized with an overdose of metophane and decapitated, whereafter the entire uterus was removed and placed on ice. The crown-rump length (CRL) was used for determination of embryonic stage. A tail sample was dissected from each fetus, and the kidneys were examined by blunt dissection from the dorsal spine. As shown previously, all GDNF - / - fetuses lacked kidneys, and the heterozygotes had developmental abnormalities in at least one kidney. The tail sample was kept on ice until all dissections had been performed, and thereafter DNA was extracted for genotyping (see below). Fetal VM tissues from $13 \mathrm{WT}, 25$ heterozygous, and 19 GDNF $-/$ - fetuses at E14-15 were grafted bilaterally to the striatum in 31 MPTP lesioned mice, so that each recipient contained one type of graft on one side and a second type of transplant contralaterally. Grafts of ventral mesencephalon from three WT, three heterozygote, and four GDNF $-/$ - fetuses were immersed in human recombinant GDNF (6 nM) in PBS, or PBS alone, for $30 \mathrm{~min}$ before grafting. The VM area from one hemisphere was immersed in GDNF, and VM tissues from the opposite hemisphere of the same fetus always served as a vehicle-treated control. Transplants were placed at the following coordinates: $1.0 \mathrm{~mm}$ anterior of Bregma, 1.5 $\mathrm{mm}$ lateral, and $5 \mathrm{~mm}$ deep [see the stereotaxic mouse atlas by Franklin and Paxinos (1997)]. The stereotaxic needle was placed at the coordinates described and was then retracted $0.5 \mathrm{~mm}$ before injection of the transplanted tissue. The burr hole was covered with bone wax, and the skin overlying the injection site was sutured and washed with iodine and $70 \%$ ethanol. All procedures were approved by the local animal care and use committee and adhered to the standard National Institutes of Health protocols for animal use.

PCR genotyping. Genomic DNA was prepared from a $1 \mathrm{~cm}$ tail cutting of fetal mice and graft recipients. The tail was homogenized in $0.2 \mathrm{M}$ $\mathrm{NaCl}, 5 \mathrm{~mm}$ EDTA, $100 \mathrm{~mm}$ Tris, $\mathrm{pH} \mathrm{8.5,0.2 \%} \mathrm{SDS,} \mathrm{and} 400 \mu \mathrm{g} / \mathrm{ml}$ proteinase $\mathrm{K}$ overnight at $55^{\circ} \mathrm{C}$. The suspension was then centrifuged to remove debris, and the DNA in the supernatant was precipitated with 1 vol of isopropanol, pelleted, washed once with $70 \%$ ethanol, and resuspended in $20 \mu \mathrm{l}$ sterile water. The DNA was assayed for the presence of the GDNF wild-type or knock-out allele in two separate PCR reactions using GDNF wild-type- or knock-out-specific primers. PCR was performed in a total reaction volume of $50 \mu$ l, which contained $2 \mu \mathrm{l}$ of genomic DNA, $2 \mu \mathrm{M}$ of each primer, $5 \mathrm{mM} \mathrm{MgCl}_{2}, 200 \mu \mathrm{M}$ each dATP, dGTP, dCTP, and dTTP, and 1 U Taq polymerase. The genomic DNA was amplified for a total of 35 cycles, and the products were analyzed for the presence of the WT or GDNF $-/-$ allele on a $1.5 \%$ agarose gel. Amplification of the WT allele gives a band of $344 \mathrm{bp}$, whereas the mutant allele gives a band of 255 bp (Pichel et al., 1996).

Immunocytochemistry. Transplants were studied at 8 weeks after grafting, when the recipient mice were killed and processed for tyrosine hydroxylase (TH) immunohistochemistry of graft and host brain tissue. Mice with intracranial grafts were deeply anesthetized with chloral hydrate $(600 \mathrm{mg} / \mathrm{kg}$, i.p.) and perfused transcardially with $0.9 \% \mathrm{NaCl}$ followed by $4 \%$ paraformaldehyde and $2 \%$ picric acid in $0.1 \mathrm{M}$ PBS. Brains were removed and post-fixed for $24 \mathrm{hr}$, then transferred to $30 \%$ sucrose in $0.1 \mathrm{M}$ PBS for a minimum of $16 \mathrm{hr}$. Sections from host striatum and midbrain were prepared and processed for TH immunohistochemistry according to our standard protocols (Granholm et al., 1997a,b). Controls included sections incubated in the absence of primary or secondary antibody as well as preincubation with the appropriate antigen. To control for intergroup staining variability, all steps of the immunohistochemical staining, including the DAB reaction, were performed in the same solutions and times for all groups using tissue wells with plastic mesh bottoms on an orbital shaker table. Cresyl violet staining was performed on every sixth section throughout the transplants to verify the graft placement sites and extension.

Image analysis of cells per section and TH staining intensity. Image analysis of innervation staining density and number of cells per section was performed on every sixth section throughout the intracranial grafts using the NIH Image analysis program. Because systematic random sampling using standard stereological techniques requires a total sampling number of $\sim 150-300$ cells per animal to achieve reliable total cell number estimations and an adequate coefficient of error (Gundersen et al., 1988), we were not able to perform the optical fractionator method for total cell counts in the present study. As can be seen in Results, most transplants from GDNF - / - fetuses contained a total of only one to five cells in each section, which was not sufficient for stereological measurements. Instead, we used a standardized counting grid and the N IH Image software and estimated cells per section as well as density of TH immunostaining in an area of $1 \mathrm{~mm}$ surrounding each transplant/host interface. The image analysis measurements were performed blindly by two independent investigators from which means were then established. Image is written using Think Pascal from Symantec Corporation, and the complete source code is freely available. Image can be used to measure area and average gray value, as well as path lengths and angles of cellular components. Spatial calibration is supported to provide real world area and length measurements. Density calibration was performed against an optical density calibration curve that takes into account and subtracts the background from each section that is measured. The gray scale value is within the range of $0-256$, where 0 represents white. The first, most rostral section of the transplant was selected randomly for each animal, and thereafter, every sixth section was stained for TH immunohistochemistry, as described above, throughout the entire intracranial transplant. Because the sections were $30 \mu \mathrm{m}$ in thickness, this rendered a sample distance of $>150 \mu \mathrm{m}$ to ensure that no neuron was counted twice. To further ensure that treatments were equal among the different groups, sections from all groups were processed together simultaneously as described above. An additional level of control for variability is provided by the fact that transplants from different groups were placed on opposite sides of the same WT host brain, allowing evaluation of staining density and cell number to be performed for two different groups and treatments on the same section of host brain. Staining density measurements revealed that background staining was within five staining units from each other in each group, further supporting equal treatment during staining. Only cells that exhibited a visible nucleus and at least two processes were characterized as TH-immunoreactive neurons. Statistical analyses were performed using Statview and ANOVAs with Scheffé's post hoc analysis.

\section{RESULTS}

\section{Grafts to MPTP-treated host animals}

Host WT animals given MPTP showed a profound loss of TH immunoreactivity from the VM cell body area (Fig. $1 A$ ) as well as the target striatum area (Fig. $1 C$ ), compared with saline-injected WT controls (Fig. 1B,D). Some TH-positive neurons were still present in MPTP-treated substantia nigra, but there was $>50 \%$ loss of nigral cell bodies with the treatment, and a $60-80 \%$ loss of TH immunoreactivity in the striatum (Fig. $1 C, D$ ). This level of dopamine denervation in the striatum agrees with previous studies using a similar dosing regimen (Tomac et al., 1995).

Most intracranial transplants were placed in the medial portion of the striatum or medially in the lateral septal nucleus or the accumbens (Fig. $1 E, F)$. In some cases (Fig. $1 F$ ), the transplanted tissue resided in the lateral ventricle. There was no difference between the transplant groups in terms of placement of the 

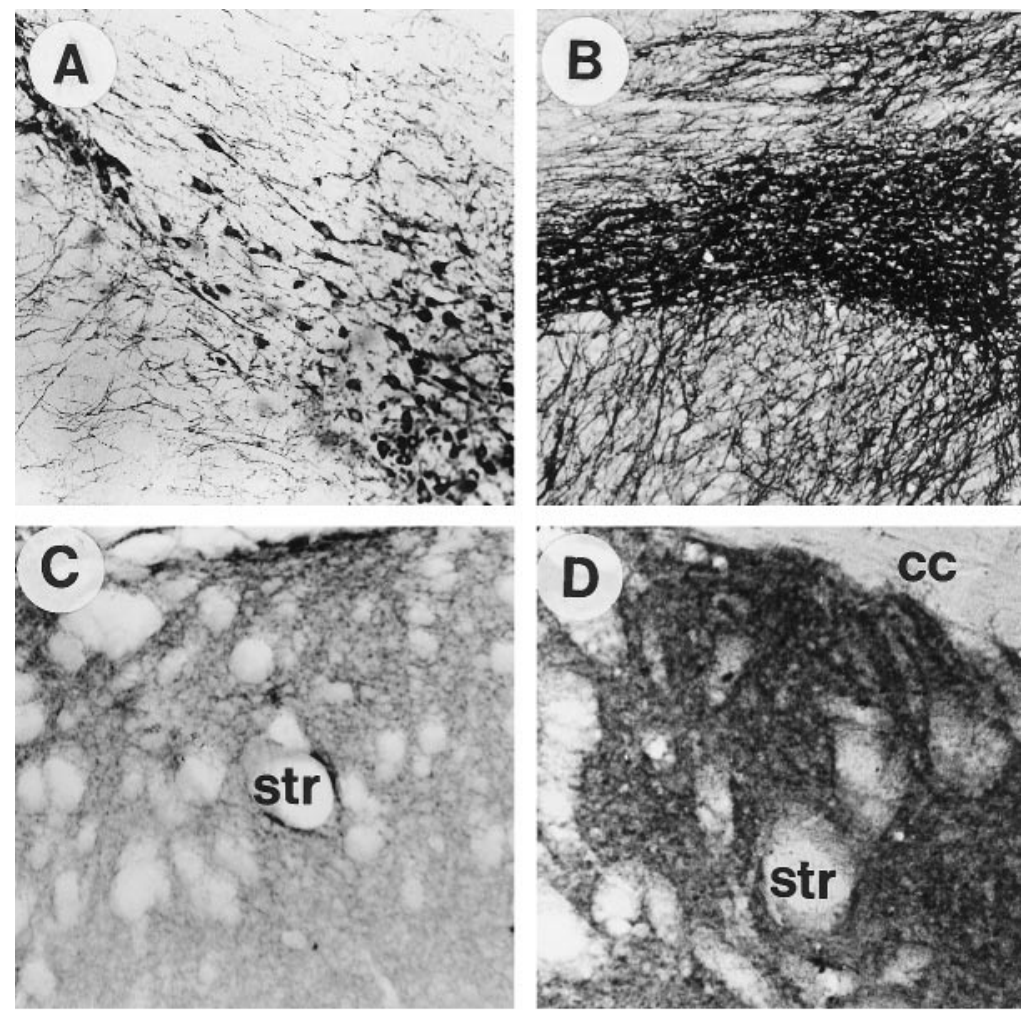

Figure 1. $A, B$, Tyrosine hydroxylase (TH) immunohistochemistry on sections from mouse midbrain; $C, D$, TH staining from the striatum of adult mice. The average $\mathrm{TH}$ staining pattern in mice that have been lesioned with MPTP $(A, C)$ compared with the staining pattern seen in an intact adult wild-type mouse $(B$, $D$ ) is demonstrated in this figure. Note the sparse distribution of TH-positive neurons in the MPTP-treated substantia nigra $(A)$ and striatum $(C)$, compared with the nontreated control $(B, D)$. $E$ and $F$ represent two transplants from a GDNF $-/-$ donor $(E)$ and a wild-type donor $(F)$ at 8 weeks after grafting. These cresyl violet-stained sections demonstrate the most common placement of the transplants as well as the relative size of the two graft types (transplants from wild-type donors were on average twice as large as transplants from GDNF - / - fetuses). Arrows, $\mathrm{Graft} /$ host border; Str, striatum; $c c$, corpus callosum; $t p$, transplant; $l v$, lateral ventricle. Scale bar (shown in $F$ ): $A, B, 50 \mu \mathrm{m}$; $C-F, 100 \mu \mathrm{m}$.
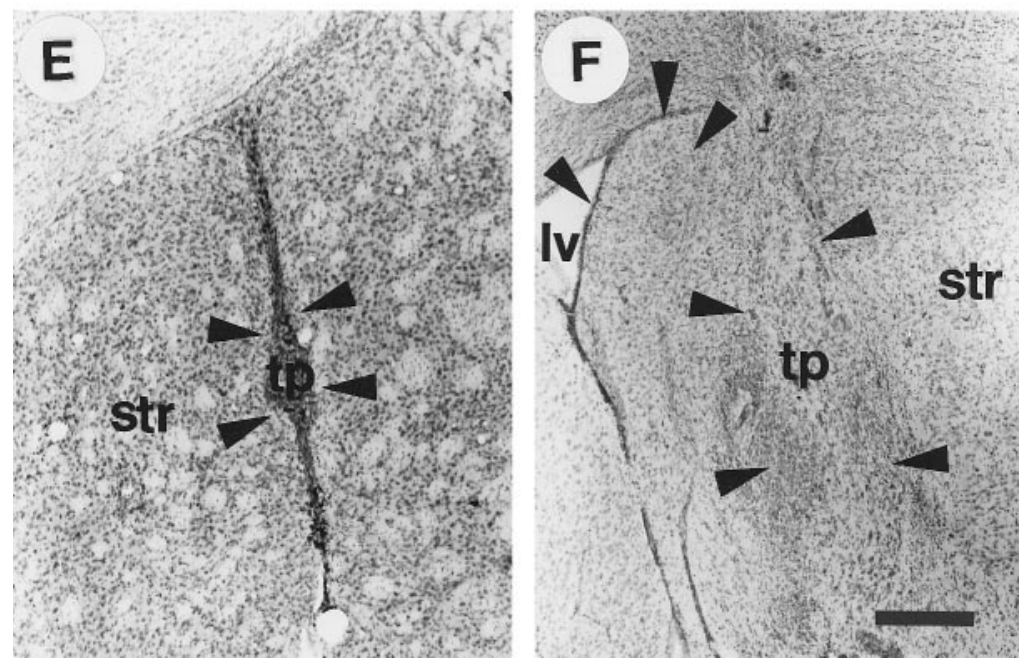

transplants in the brain. However, the wild-type grafts grew on average twice as much as the grafts from GDNF $-/$ - donors to reach a greater final size, regardless of placement in the brain. It was sometimes difficult to discern the border between graft and host, because the grafted tissue was well integrated with the host brain 8 weeks after grafting. As can be seen in Figure 1, $E$ and $F$, the wild-type transplants contained both large neurons and smaller cells, presumably glial cells (Fig. 1F). Cresyl violetstained sections, combined with $\mathrm{TH}$ sections shown in Figures $2-5$, revealed that the wild-type transplants contained many cells that were not DA. The tissue from GDNF $-/-$ donors, on the other hand, appeared to contain numerous macrophages and glial cells (Fig. $1 E$ ) and very few large neuron-like cells. Preliminary studies have demonstrated a significant amount of TUNELlabeled cells in these transplants (Granholm et al., 1998), suggesting that programmed cell death may be quite prevalent in the GDNF -/ - tissue after grafting to adult wild-type hosts.
TH immunohistochemistry was performed on intracranial transplants 8 weeks after grafting to determine the extent of dopamine neuron cell bodies and host brain innervation from the different grafts. The VM transplants from WT fetuses (Fig. $2 A, B$, $w t$ ) exhibited a dense plexus of $\mathrm{TH}$-immunoreactive cell bodies and neurites within the grafted tissue, whereas transplants from heterozygous hosts $(+/-)$ contained a medium density of THpositive cells (Fig. $2 C, D$ ). Only a sparse number of TH-positive neurons could be found in the VM grafts from GDNF-/- tissue (Fig. $2 E, F)$, as compared with grafts from WT fetuses. Of the 19 GDNF - / - transplants performed, only 14 contained identifiable transplanted tissue at all, and of these 14 transplants only 4 contained any TH-immunoreactive neurons whatsoever. This contrasts with robust growth and DA neuron survival in 11 of the 13 wild-type transplants. As shown in Figure 2, this marked reduction in $\mathrm{TH}$-immunoreactive cell bodies was coupled with a paucity of TH-positive nerve cell processes, both within -/- 

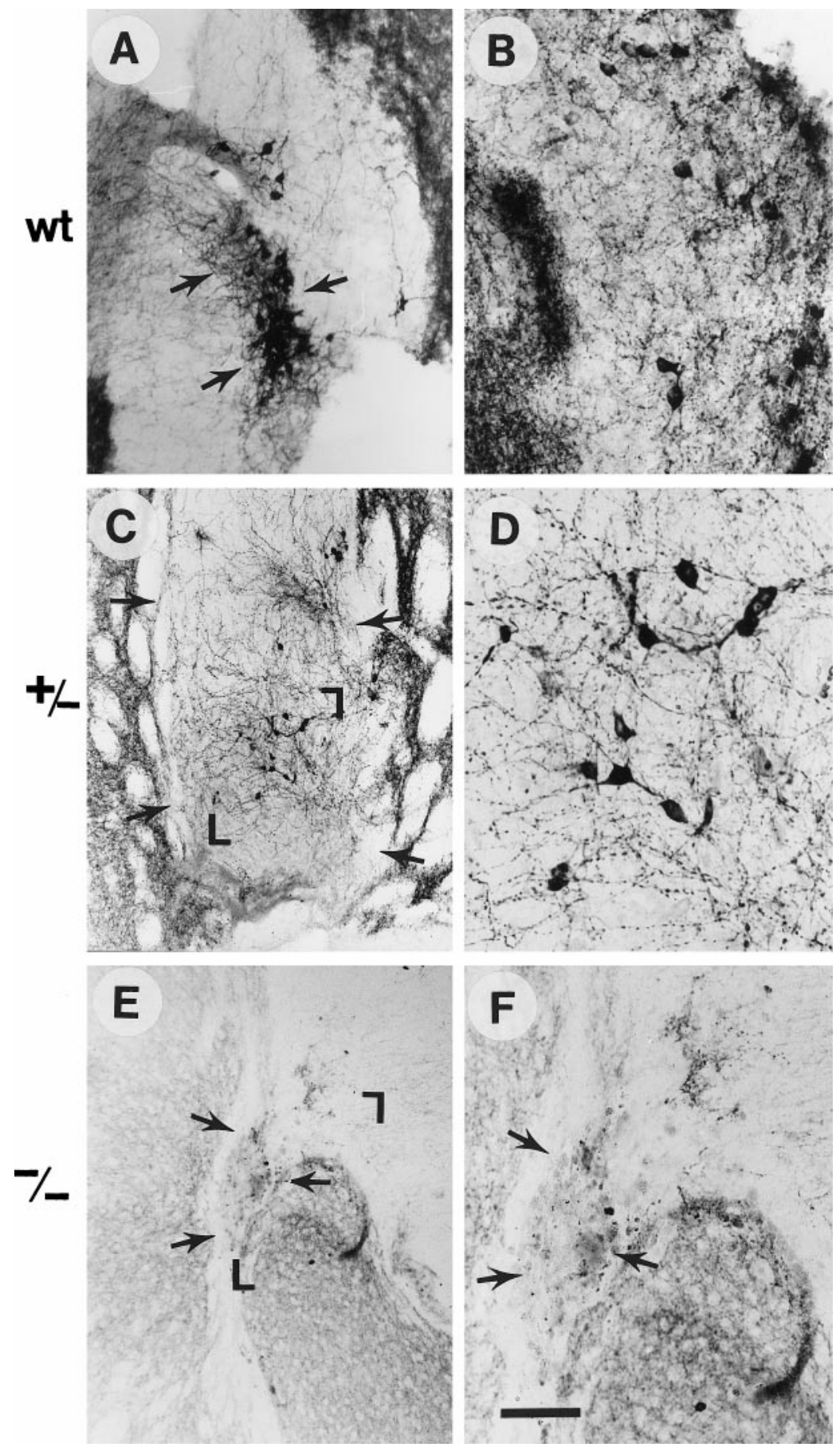

Figure 2. TH immunocytochemistry of grafts from WT $(A, B), \mathrm{GDNF}+/-(C, D)$, and GDNF $-/-(E, F)$ donors. $D$ and $F$ are larger magnifications of the grafts shown in $C$ and $E$, respectively, whereas $B$ represents a high magnification of a wild-type graft other than the one seen in A. Arrows delineate grafts, and the magnified areas are demarcated with corners in $C$ and $E$. Note the much greater TH-immunoreactive cell numbers and fiber outgrowth in WT compared with -/grafts, which were virtually devoid of TH-positive neurons and neurites and, additionally, contained a large number of macrophages. The $+/-$ grafts had an intermediate number of TH-positive cells and fibers. Scale bar (shown in $F$ ): $A, 70 \mu \mathrm{m}$; $C, E, 100 \mu \mathrm{m} ; B, D, F, 30 \mu \mathrm{m}$. grafts and in the surrounding host brain, whereas both heterozygous (Fig. $2 C, D$ ) and WT (Fig. $2 A, B$ ) grafts exhibited a dense plexus of fibers innervating the surrounding host brain. Morphological assessment suggested that there was a $>80 \%$ overall reduction of TH-stained neuronal cell bodies in the grafts from GDNF-/- animals, compared with transplants from WT donor tissue (Fig. 2).

Image analysis measurements revealed significant differences in the number of $\mathrm{TH}$-immunoreactive neurons per section between the transplant groups (Fig. 3). The fewest cells per section are seen in the GDNF $-/-$ group (a mean value of $4 \pm 2.6$ cells per section; $n=6)$. An intermediate number is found in $+/-$ grafts (mean $31 \pm 5$ cells per section; $n=7$ ), and the highest number is observed in the transplants from WT fetuses (mean value per section $77 \pm 7 ; n=3$ ). Statistical analysis using ANOVA revealed a significant difference at the level of $p<0.001$ among all groups, except for that between the GDNF $-/-$ and the heterozygous grafts, where there was a significant difference at a level of $p<0.01$ (ANOVA with Scheffé's post hoc analysis). The staining intensity of TH immunoreactivity was also assessed with the same image analysis system (see details in Materials and Methods section), estimating the staining intensity subtracted from background on a calibrated gray scale where $0=$ white and 256 = black in a $1 \mathrm{~mm}$ rim surrounding the graft/host interface. The values for these density measurements are shown in Figure 3 as well. There were significant reductions in the mean TH stain- 

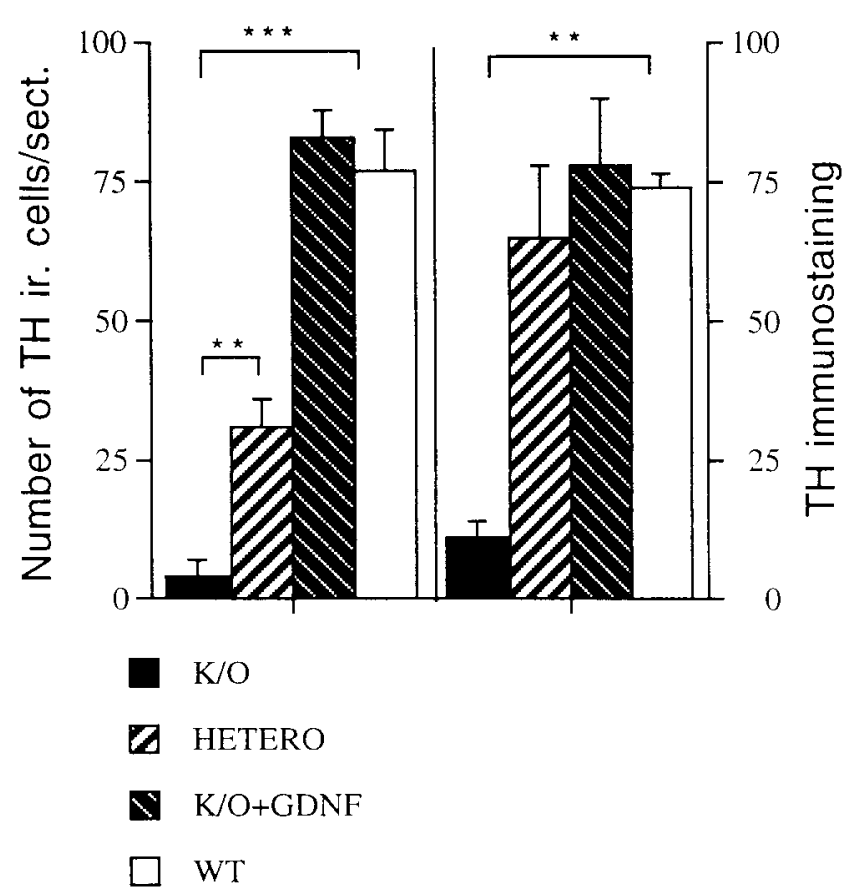

Figure 3. Bar graph depicting both the number of TH-positive cells per section (left) and the staining intensity in a $1 \mathrm{~mm}$ halo surrounding the graft/host border (right). The staining intensity (right graph) is expressed as a mean value subtracted from background on a standardized gray scale ranging from 0 (white) to 256 (black). The left graph depicts the mean number of neurons per section from transplants in the different groups. The group legends are depicted underneath the graph. As can be seen from this bar graph, transplants from GDNF $-/-$ fetuses contained significantly fewer TH-positive neurons than the other groups and also had a marked decrease in the $\mathrm{TH}$ staining intensity surrounding the graft/host border (right). Only four transplants of $-/-$ tissue contained any TH-positive neurons. However, GDNF $-/-$ transplants treated with GDNF in the preincubation buffer (striped bars) did not differ from WT controls, either in number of cells per section or in staining density. Thus, GDNF treatment appeared to normalize these two parameters of dopamine cell survival in the $-/-$ grafts. Heterozygous grafts (Hetero) contained fewer mean cells per section than the WT controls, but the innervation density was similar. Statistical results were obtained with ANOVA and Scheffé's post hoc analysis. ${ }^{* *} p<0.01 ;{ }^{* * *} p<0.001$.

ing density in the transplants from GDNF - /- grafts (mean staining density was $11 \pm 3 ; n=6$; SEM). The mean staining density for heterozygous grafts was $65 \pm 13$ ( $n=7$; SEM), and for WT grafts it was $74 \pm 2.5(n=3$; SEM). ANOVA analysis with Scheffé's post hoc test revealed a significant difference between WT and GDNF $-/-$ grafts $(p<0.01)$ as well as between GDNF $-/-$ grafts and heterozygous grafts $(p<0.01)$. Despite the fact that the heterozygous grafts contained significantly fewer cells than the WT grafts (Fig. 3), the staining density for TH did not differ between heterozygous and WT grafts.

\section{Effects of GDNF exposure}

To determine whether the changes in GDNF - / - transplant DA neuron survival was caused by the lack of GDNF or by secondary factors in the fetus, WT and $-/-$ grafts $(n=4)$ were treated by immersion in GDNF solution (6 nM for $30 \mathrm{~min}$ ) before transplantation. We have demonstrated previously that GDNF immersion before transplantation results in increased cell survival and fiber outgrowth from rat fetal VM tissue into the adult rat (Granholm et al., 1997a,b), and we found a similar effect on the fetal mouse WT grafts to the adult brain in the present study (Fig. 4A-D).
Both the overall appearance and the fiber density were enhanced in WT grafts treated with GDNF (Fig. 4A,B), compared with WT grafts without GDNF pretreatment (Fig. $4 C, D$ ). A more dramatic difference, however, was observed in GDNF - / - tissue treated with GDNF before transplantation to adult WT host. The number of TH-immunoreactive nerve cells per section, as well as fiber outgrowth in the graft/host border, was markedly increased by GDNF exposure when studied at the 8 week time point (Figs. $3,5)$. Figure $5 A$ depicts a section of an MPTP-treated mouse brain containing a GDNF $-/$ - transplant without GDNF treatment (left) and contralateral to this graft, a GDNF - / - graft treated with GDNF (right). Note the marked alteration in size, staining, and fiber growth after GDNF treatment of the graft. The fetal VM tissue originated from the same fetus in both cases. Morphological assessment suggested that GDNF pretreatment normalized the appearance of $\mathrm{TH}$ immunoreactivity in GDNF $-/-$ grafts (Fig. 5). The mean cell number per section of GDNFtreated $-/-$ grafts was not statistically significant from that seen in transplants from WT donors (Fig. 3) (mean value $83 \pm 5 ; n=$ 3; SEM), and the mean staining intensity with $\mathrm{TH}$ antibodies was also similar to that seen in WT hosts (mean value $78 \pm 12 ; n=$ 3; SEM). However, both of these values differed significantly from the mean values seen in the GDNF $-/-$ transplants that were not treated with GDNF $(p<0.001)$ (Fig. 3).

\section{DISCUSSION}

In this study we used intrastriatal grafts of fetal VM tissue to the striatum of adult wild-type mice and found that GDNF is required for postnatal maturation of midbrain DA neurons. Grafts from $-/-$ fetuses showed little or no DA neuron survival and fiber outgrowth. Moreover, the DA phenotype in such tissue could be restored by immersion in GDNF before grafting, and this treatment gave rise to cell densities and innervation densities that were not different from those observed in transplants from WT donors. This study also presents a unique method for evaluating continued development and innervation properties of a neuronal population that would otherwise die at birth because of peripheral side effects of the null mutation.

The question arises as to why the absence of GDNF in early fetal development leads to postnatal loss of DA cells in GDNF-/ - transplants to adult wild-type hosts when the DA neurons appear normal in the null mutation in newborn animals (Moore et al., 1996; Pichel et al., 1996; Sanchez et al., 1996). In this context, it is important to remember that GDNF is present in the nigrostriatal pathway during prenatal and early postnatal development but is virtually absent in the adult CNS (Strömberg et al., 1993). Thus, the grafted fetal dopamine cells did not have a source for GDNF in the adult striatal environment to which they were grafted. One possibility is that locally synthesized and secreted GDNF in the WT graft, and to a lesser extent in the heterozygotes, regulates the degree of apoptosis and postnatal DA neuron survival. The absence of GDNF in the GDNF-/transplant would lead to increased apoptosis and minimal survival. The "rescue" of DA neurons by acute GDNF exposure in -/ - tissue at E14-15, before grafting, could be attributable to the relatively high concentrations of GDNF used for immersion, almost 100 -fold greater than the $\mathrm{ED}_{50}$ for receptor binding. The $\mathrm{ED}_{50}$ for the interaction of GDNF with the GFR $\alpha$ - 1 receptor has been found to be 40-60 pM (Jing et al., 1996; Treanor et al., 1996). Another factor could be the relatively long half-life of GDNF in CNS tissue. The half-life of GDNF injected into brain has been estimated at 3-4 d, and after intracerebroventricular 

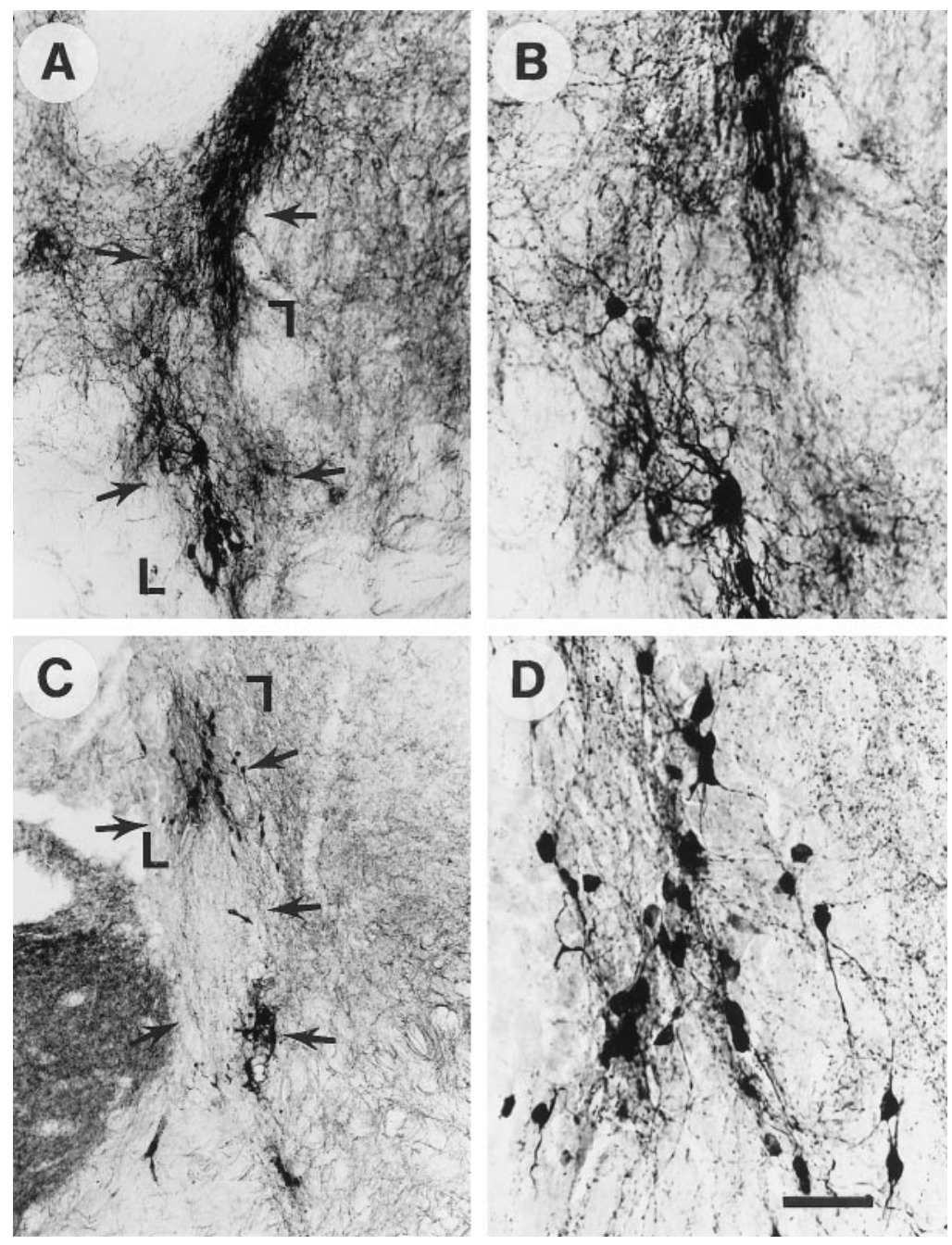

Figure 4. Effects of $6 \mathrm{~nm}$ GDNF pretreatment on WT grafts shown by TH immunocytochemistry. Arrows delineate transplants. $A, B$, WT grafts after GDNF pretreatment. $C, D, \mathrm{WT}$ grafts without GDNF pretreatment. The areas shown in higher magnification $(B, D)$ are outlined with corner markers in $A$ and $C$. Note the increased TH cell survival and fiber outgrowth after GDNF exposure, even in wild-type grafts. Scale bar (shown in $D): A, C, 100 \mu \mathrm{m} ; B, D, 40 \mu \mathrm{m}$. injection, GDNF is present in brain for at least $7 \mathrm{~d}$ (Lapchak et al., 1997). In this context, GDNF could function as an autocrine or paracrine molecule. In addition, it has been shown (Hudson et al., 1995) that the effects of GDNF on midbrain DA neurons last for at least 3 weeks after a single intracranial injection in vivo so that acute pretreatment with this protein could also manifest the extended effects on the tissue grafts reported here. Thus, a single pretreatment with the trophic molecule at the time of grafting would extend its effects well beyond the critical time for cell survival of grafted dopamine neurons, which has been determined to extend 2 weeks after grafting (Mahalik et al., 1994; Kaddis et al., 1996; Clarkson et al., 1997).

Alternatively, it may be postulated that GDNF in the mid-late fetal period influences an as yet unknown process that determines the subsequent degree of apoptosis 2-4 weeks later. The time course of midbrain DA neuron apoptosis in the developing rat has been studied in detail (Oo and Burke, 1997), with two peaks occurring at P2 and P14. This would correspond to 1 week and 3 weeks after grafting, respectively, in the present study. It has also been demonstrated that apoptosis is present in VM dopamine neuron transplants and occurs at similar times as those in situ (Mahalik et al., 1994; Zawada et al., 1998; Schierle et al., 1999). The extent of apoptosis in many central and peripheral neuronal populations, including midbrain DA neurons, depends on target innervation and/or trophic factor exposure. (Kelly and Burke,
1996; Haviv et al., 1997; Marti et al., 1997). Because GDNF has been demonstrated to be a target-derived trophic factor (Strömberg et al., 1993; Tomac et al., 1995), it is more likely to exert survival-promoting activity on DA neurons during the time of target innervation rather than during earlier fetal development, when phenotypic differentiation occurs (Marti et al., 1997). Indeed, in situ hybridization studies have shown prominent GDNF mRNA expression in striatum during the first 2 postnatal weeks in the rat, the time during which connectivity between dopamine afferent fibers and striatal neurons develops in this species, and also the time period when the major apoptotic events occur in these neurons (Strömberg et al., 1993; Marti et al., 1997; Oo and Burke, 1997). Supporting the hypothesis of GDNF as a survival factor for dopamine neurons, we have recently shown that combined treatment with GDNF and caspase inhibitors enhances DA cell survival and fiber outgrowth in fetal VM grafts from normal fetal rat donors into the anterior eye chamber of adult rats (Granholm et al., 1999). The present findings suggest that GDNF may also act as a survival factor for dopamine neurons in the mouse. An important question that arises from the present studies is whether the GDNF null mutation gives rise to a general cell death within the grafted tissue or whether this occurs exclusively in the neurons of DA phenotype. Preliminary results from our lab indicate that both striatal and hippocampal tissues from fetal GDNF knockout donors survive well when grafted to the adult 
Figure 5. Effects of $6 \mathrm{~nm}$ GDNF pretreatment on $-/-$ grafts shown by TH immunocytochemistry. $A$, Low-power photomicrograph showing $-/-$ transplants without GDNF immersion (left graft) and with GDNF immersion (right graft) within the same brain. $B, C$, GDNF $-/-$ grafts with GDNF pretreatment. $D, E$, GDNF -/grafts without GDNF pretreatment. The areas shown at higher magnification in $C$ and $E$ are outlined with corner markers in $B$ and $D$, respectively. Note markedly increased numbers of TH-positive cells as well as fiber outgrowth after GDNF pretreatment. The -/transplant pretreated with vehicle was virtually devoid of THpositive cells and fiber outgrowth. The sparse plexus of $\mathrm{TH}-$ immunoreactive neurites in the striatum of the host in $D$ and $E$ most likely originates from spared innervation from the host nigra, because MPTP produces only a partial dopamine denervation in mice. The GDNF - $/$ - transplant shown in $D$ and $E$ contained numerous larger cells reminiscent of macrophages ( $D$, bottom arrow). Arrows delineate transplants. Scale bar in (shown in $E$ ): $A, 200 \mu \mathrm{m} ; B, 100$ $\mu \mathrm{m} ; D, 65 \mu \mathrm{m} ; C, E, 40 \mu \mathrm{m}$.
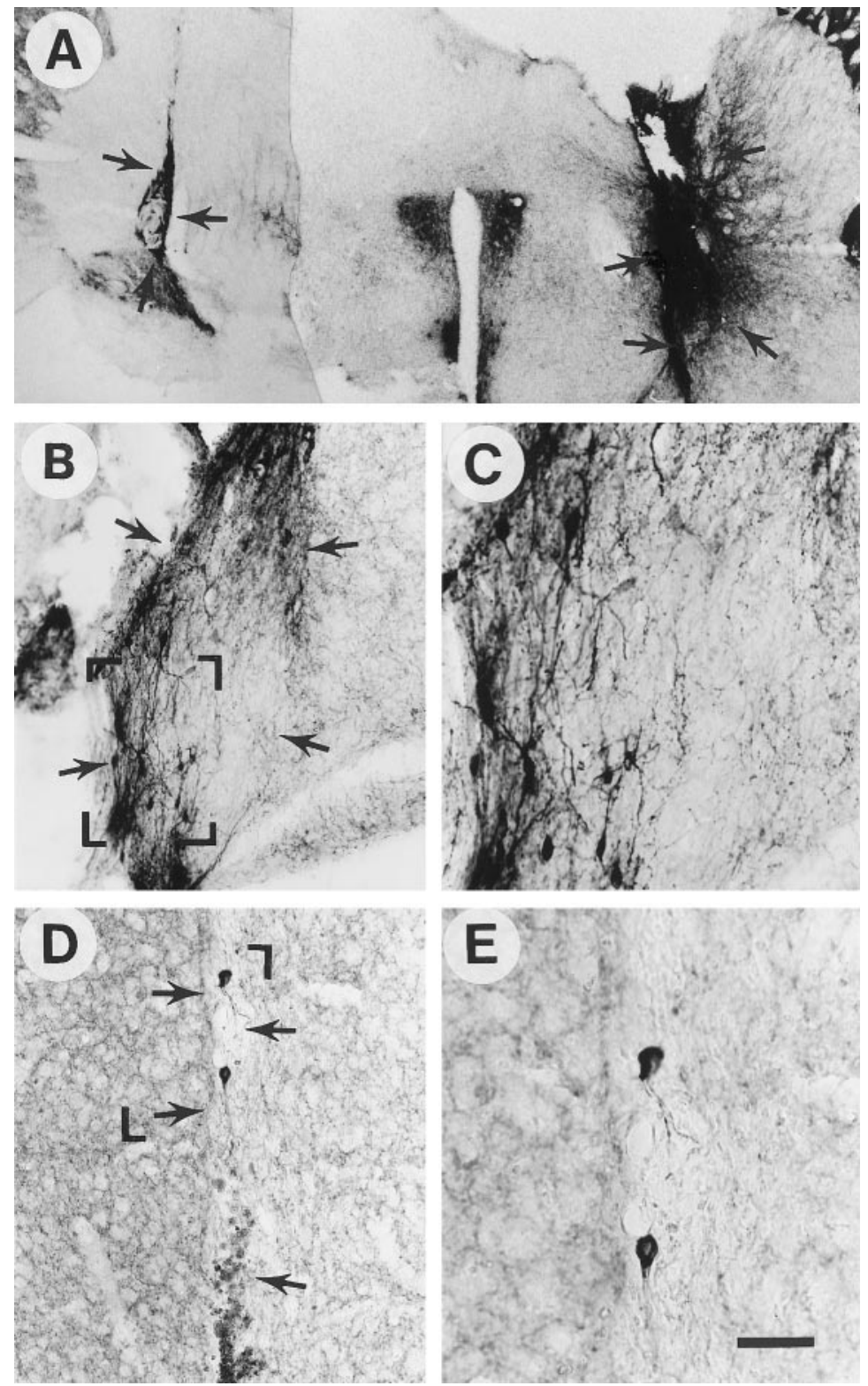

WT mouse host, whereas grafted central noradrenergic and DA neurons do not. Thus, the effect of the GDNF null mutation on DA neurons does not seem to be a general cell death effect per se but a more specific influence that alters the survival of certain neuronal phenotypes in the brain.

Our studies also have implications for the pharmacotherapy of PD. Despite a wealth of research in this area, the triggering mechanisms underlying the slow degeneration of the dopamine neurons are still largely unknown. Some recent hypotheses are that PD is caused by initial mitochondrial oxidative dysfunction resulting in premature apoptosis or loss of phenotype in the DA population, accumulation of reactive oxygen species, deficient trophic factors and/or cytokines, or a combination of all of these events (Fahn and Cohen, 1992; Ruberg et al., 1997). It has been suggested that the initial stages in Parkinson's disease may involve a loss of the DA terminal fields in caudate and putamen. Such a decrease in target innervation, coupled with metabolic injury and low levels of trophic factors in the adult brain, could lead to increased midbrain DA neuron cell death or phenotypic loss. Exogenous administration of trophic molecules like GDNF might slow this process and increase the window of efficacy for more conventional pharmacotherapy.

In conclusion, we have studied the maturation of central dopamine neurons from GDNF $-/-,+/-$, and WT sibling mice grafted into the brain of adult MPTP-lesioned WT animals. This approach allowed us to evaluate the effects of a lack of a trophic factor in a discrete neuronal population and how this relates to normal neuronal development and target innervation. These studies provide a method in which the continued development and maturation of neuronal pathways from trophic factor knockout strains may be studied many months beyond the life cycle of the knockout mouse. Previously, it has not been possible to study these processes, because the neurotrophic factor knockout mice often die shortly after birth (Granholm and Hoffer, 1999). Our findings strongly suggest that GDNF may be critical for the long-term survival of VM dopamine neurons, especially with altered target innervation. It is possible that the fetal dopamine neurons from the GDNF -/- donors would have survived better 
if grafted in a neonatal wild-type mouse, where fairly high quantities of GDNF are still produced in the striatum, rather than the adult recipients used here. However, transplantation into the mouse brain is technically difficult, and the transplantation surgery would not have been as consistent using neonatal recipients.

One obvious question that arises from these studies is whether GDNF only aids in the survival of damaged neurons, such as occurs during the dissection of fetal tissue or after neurotoxic lesions, or if it has a significant role in the normal development of the dopamine neurons as well. The experimental model presented here would not directly answer this question because the transplanted neurons undergo axotomy when they are dissected, but in situ hybridization studies have shown high levels of GDNF in the fetal and early postnatal striatum, suggesting a role for this trophic factor during normal development (Schaar et al., 1993; Choi-Lundberg et al., 1995; Nosrat et al., 1996). Although the grafted neurons may be damaged at the time of grafting, surviving neurons soon regain their developmental schedule and become completely integrated and develop functional synapses with the host to which they are grafted (Mahalik et al., 1989).

Finally, using the method described herein, it is possible to determine the specific role of a trophic factor for long-term target innervation and functional integration in the adult brain, and it is also possible to rule out adaptive mechanisms occurring in many of the developmental defects incurred by targeted gene deletion experiments. Thus, transplantation of trophic factor knockout tissue and replacement therapy represents a powerful and novel technique for further evaluating specific biological mechanisms of neural development and maintenance.

\section{REFERENCES}

Bernheimer H, Birkmayer W, Hornykiewicz O, Jellinger K, Seitelberg F (1973) Brain dopamine and the syndromes of Parkinson and Huntington. J Neurol Sci 20:415-455.

Bowenkamp KE, Hoffman AF, Gerhardt GA, Henry MA, Biddle PT, Hoffer BJ, Granholm A-C (1995) Glial cell-line derived neurotrophic factor supports survival of injured midbrain DA neurons. J Comp Neurol 355:479-489.

Choi-Lundberg DL, Bohn M (1995) Ontogeny and distribution of glial cell line-derived neurotrophic factor (GDNF) mRNA in rat. Dev Brain Res 85:80-88.

Clarkson ED, Zawada WM, Freed CR (1997) GDNF improves survival and reduces apoptosis in human embryonic DA neurons in vitro. Cell Tissue Res 289:207-210.

Creedon DJ, Tansey MG, Balow RH, Osborne PA, Lampe PA, Fahrner TJ, Heuckeroth RO, Milbrandt J, Johnson EM (1997) Neurturin shares receptors and signal transduction pathways with glial cell linederived neurotrophic factor in sympathetic neurons. Proc Natl Acad Sci USA 94:7018-7023.

Fahn S, Cohen G (1992) The oxidant stress hypothesis in Parkinson's disease: evidence supporting it. Ann Neurol 32:804-812.

Franklin KBJ, Paxinos G (1997) The mouse brain in stereotaxic coordinates. New York: Academic.

Gash DM, Zhang Z, Ovadia A, Cass WA, Simmerman AY-L, Russell D, Martin D, Lapchak PA, Collins F, Hoffer BJ, Gerhardt GA (1996) Functional recovery in parkinsonian monkeys treated with GDNF. Nature 380:252-255.

Granholm A-C, Mott JL, Bowenkamp K, Eken S, Henry S, Hoffer BJ, Lapchak PA, Palmer MR, van Horne C, Gerhardt GA (1997a) Glial cell line-derived neurotrophic factor improves survival of ventral mesencephalic grafts to the 6-hydroxydopamine lesioned striatum. Exp Brain Res 116:29-38.

Granholm, A-C, Srivastava N, Mott JL, Henry S, Henry M, Westphal H, Pichel JG, Shen L, Hoffer BJ (1997b) Morphological alterations in the peripheral and central nervous systems of mice lacking glial cell linederived neurotrophic factor (GDNF): immunohistochemical studies. J Neurosci 17:1168-1178.

Granholm A-C, Sanders LA, Reyland ME, Hoernig GR, Shen L, Hoffer BJ, Westphal H (1998) Transplantation of fetal tissues from trophic factor knockout mice to wildtype and heterozygous siblings. Clearwater, FL: American Society for Neural Transplantation Abstract.

Granholm A-C, Hoffer BJ (1999) Is trophic factor gene disruption a "Knockout" model for Parkinson's disease? In: Central nervous system diseases (Emerich DF, Dean III RL, Sanberg PR, eds), pp 227-246. Totowa, NJ: Humana.

Granholm A-C, Helt C, Hoernig G, Strömberg I, Gerhardt GA, Reyland MA, Quissell D (1999) Combined treatment with GDNF and caspase blockers enhances cell survival and fiber outgrowth in fetal ventral mesencephalic grafts [Abstr]. Am Soc Neural Transpl.

Gundersen HJG, Bagger P, Bendtse TF, Evans SM, Korbo L, Marcussen N, Möller A, Kielsen K, Nyengaard JR, Pakkenberg B, Sörensen FB, Vesterby A, West MJ (1988) The new stereological tools: dissector, fractionator, nucleator and point sampling intercepts and their uses in pathological research and diagnosis. APMIS 96:857-881.

Haviv R, Lindenboim L, Li H, Yuan J, Stein R (1997) Need for caspases in apoptosis of trophic factor-deprived PC12 cells. J Neurosci Res 50:69-80.

Hoffer BJ, Hoffman A, Bowenkamp K, Huettl P, Hudson J, Martin D, Lin L-FH, Gerhardt G (1994) Glial cell line-derived neurotrophic factor reverses toxin-induced injury to midbrain DA neurons in vivo. Neurosci Lett 182:107-111.

Hornykiewicz O, Kish S (1986) Biochemical pathology of Parkinson's disease. Adv Neurol 45:19-34.

Hudson J, Granholm AC, Gerhard GA, Henry MA, Hoffman A, Biddle P, Leela NS, Mackerlova L, Lile JD, Collins F, Hoffer BJ (1995) Glial cell line-derived neurotrophic factor augments midbrain DA circuits in vivo. Brain Res Bull 36:425-433.

Jing S, Wen D, Yu Y, Holst P, Luo Y, Fang M, Tamir R, Antonio L, Hu Z, Cupples R, Louis J, Hu S, Altrock B, Fox G (1996) GDNF-induced activation of the ret protein tyrosine kinase is mediated by GDNFRalpha, a novel receptor for GDNF. Cell 85:1113-1124.

Johansson M, Friedemann M, Hoffer B, Strömberg I (1995) Effects of GDNF on developing and mature mesencephalic grafts in oculo. Exp Neurol 134:25-34.

Kaddis FG, Zawada WM, Schaack J, Freed CR (1996) Conditioned medium from aged monkey fibroblasts stably expressing GDNF and BDNF improves survival of embryonic dopamine neurons in vitro. Cell Tissue Res 286:241-247.

Kelly WJ, Burke RE (1996) Apoptotic neuron death in rat substantia nigra induced by striatal excitotoxic injury is developmentally dependent. Neurosci Lett 220:85-88.

Kotzbauer P, Lampe P, Heuckeroth R, Golden J, Creedon D, Johnson Jr E, Milbrandt J (1996) Neurturin, a relative of glial-cell-line-derived neurotrophic factor. Nature 384:467-470.

Lapchak PA, Jiao S, Collins F, Miller PJ (1997) Glial cell line-derived neurotrophic factor: distribution and pharmacology in the rat following a bolus intraventricular injection. Brain Res 747:92-102.

Leenders K, Salmon E, Tyrrell P, Perani D, Brooks D, Sager H, Jones T, Marsden C, Frackowiak R (1990) The nigrostriatal DA system assessed in vivo by positron emission tomography in healthy volunteer subjects and patients with Parkinson's disease. Arch Neurol 47:1290-1298.

Lin L-F, Doherty D, Lile J, Bektesh S, Collins, F (1993) GDNF: a glial cell line-derived neurotrophic factor for midbrain DA neurons. Science 260:1130-1132.

Lindner MD, Winn SR, Baetge EE, Hammang JP, Gentile FT, Doherty E, McDermott PE, Frydel B, Ullman MD, Schallert T (1995) Implantation of encapsulated catecholamine and GDNF-producing cells in rats with unilateral dopamine depletions and parkinsonian symptoms. Exp Neurol 132:62-76.

Mahalik TJ, Strömberg I, Gerhardt GA, Granholm A-C, Seiger Å, Bygdeman M, Olson L, Hoffer BJ, Finger TE (1989) Human ventral mesencephalic xenografts to the catecholamine-depleted striata of athymic rats: ultrastructure and immunocytochemistry. Synapse $4: 19-29$.

Mahalik TJ, Hahn WE, Clayton GH, Owens GP (1994) Programmed cell death in developing grafts of fetal substantia nigra. Exp Neurol 129:27-36.

Marti MJ, James CJ, Oo TF, Kelly WJ, Burke RE (1997) Early developmental destruction of terminals in the striatal target induces apoptosis in dopamine neurons of the substantia nigra. J Neurosci 17:2030-2039.

Moore MW, Klein RD, Farinas I, Sauer H, Armanini M, Phillips H, Reichardt LF, Ryan AM, Carvermoore K, Rosenthal A (1996) Renal and neuronal abnormalities in mice lacking GDNF. Nature 382:76-79. 
Nosrat C, Tomac A, Lindqvist E, Lindskog S, Humpel C, Ebendal T, Strömberg I, Hoffer B, Olson L (1996) Cellular expression of GDNF mRNA predicts multiple functions in and outside the nervous system. Cell Tissue Res 286:191-207.

Oo TF, Burke RE (1997) The time course of developmental cell death in phenotypically defined DA neurons of the substantia nigra. Brain Res Dev Brain Res 98:191-196.

Pichel JG, Shen L, Sheng HZ, Granholm A-C, Drago J, Grinberg A, Lee EJ, Huang SP, Saarma M, Hoffer BJ, Sariola H, Westphal H (1996) Defects in enteric innervation and kidney development in mice lacking GDNF Nature 382:73-76.

Ruberg M, Brugg B, Prigent A, Hirsch E, Brice A, Agid Y (1997) Is differential regulation of mitochondrial transcripts in Parkinson's disease related to apoptosis? J Neurochem 68:2098-2110.

Saarma M, Sariola H (1999) Other neurotrophic factors: glial cell linederived neurotrophic factor (GDNF). Microsc Res Tech 45:292-302.

Sanchez MP, Silos-Santiago I, Frisen J, He B, Lira SA, Barbacid M (1996) Renal agensis and the absence of enteric neurons in mice lacking GDNF. Nature 382:70-73.

Schaar DG, Sieber BA, Dreyfus CF, Black IB (1993) Regional and cellspecific expression of GDNF in rat brain. Exp Neurol 124:368-371.

Schierle GS, Hansson O, Leist M, Nicotera P, Widner H, Brundin P (1999) Caspase inhibition reduces apoptosis and increases survival of nigral transplants. Nat Med 5:97-100.

Schubert D, Heinemann S, Carlisle W, Tarikas H, Kimes B, Patrick J,
Steinbach JH, Culp W, Brandt BL (1974) Clonal cell lines from the rat central nervous system. Nature 249:224-227.

Strömberg I, Johnson S, Hoffer B, Olson L (1985) Reinnervation of dopamine-denervated striatum by substantia nigra transplants: immunocytochemical and electrophysiological correlates. Neuroscience 14:981-990.

Strömberg I, Björklund L, Johansson M, Tomac A, Collins F, Olson L, Hoffer B, Humpel C (1993) Glial cell line-derived neurotrophic factor is expressed in the developing but not adult striatum and stimulates developing dopamine neurons in vivo. Exp Neurol 124:401-412.

Tomac A, Lindqvist E, Lin L-FH, Ögren SO, Young D, Hoffer BJ, Olson L (1995) Protection and repair of the nigrostriatal DA system by GDNF in vivo. Nature 373:335-339.

Tomac A, Widenfalk J, Lin LH, Kohno T, Ebendal T, Hoffer BJ, Olson L (1996) Retrograde axonal transport of glial cell line-derived neurotrophic factor in the adult nigrostriatal system suggests a trophic role in the adult. Proc Natl Acad Sci USA 92:8274-8278.

Treanor J, Goodman L, Desauvage F, Stone D, Poulsen K, Beck C, Gray C, Armanini M, Pollock R, Hefti F, Phillips H, Goddard A, Moore M, Buj-Bello A, Davies A, Asai N, Takahashi M, Vandlen R, Henderson C, Rosenthal A (1996) Characterization of a multicomponent receptor for GDNF. Nature 382:80-83.

Zawada WM, Zastrow DJ, Clarkson ED, Adams FS, Bell KP, Freed CR (1998) Growth factors improve immediate survival of embryonic dopamine neurons after transplantation into rats. Brain Res 786:96-103. 